Research Article

\title{
Tribological Behavior of Mild Steel under Canola Biolubricant Conditions
}

\author{
A. Shalwan $\mathbb{D}^{1},{ }^{1}$ B. F. Yousif $\mathbb{D}^{\mathbb{D}},{ }^{2}$ F. H. Alajmi, ${ }^{2}$ and M. Alajmi ${ }^{1}$ \\ ${ }^{1}$ Department of Manufacturing Engineering Technology, Public Authority for Applied Education and Training, \\ Kuwait City, Kuwait \\ ${ }^{2}$ Faculty of Health, Engineering, and Sciences, University of Southern Queensland, Toowoomba, QLD, Australia
}

Correspondence should be addressed to A. Shalwan; ama.alajmi1@paaet.edu.kw

Received 1 July 2021; Revised 22 August 2021; Accepted 28 September 2021; Published 16 October 2021

Academic Editor: Dae-Eun Kim

Copyright (c) 2021 A. Shalwan et al. This is an open access article distributed under the Creative Commons Attribution License, which permits unrestricted use, distribution, and reproduction in any medium, provided the original work is properly cited.

\begin{abstract}
New lubricants based on vegetable oil were developed in this study. Different blends of canola oil mixed with fully synthetic two stock engine oils were developed $(0,20 \%, 40 \%, 60 \%$, and $80 \%$ of synthetic oil). The viscosity of the prepared blends was determined at different temperatures $\left(20^{\circ} \mathrm{C}-80^{\circ} \mathrm{C}\right)$. Tribological experiments were conducted to investigate the effect of the newly developed oil on the wear characteristics of mild steel material compared with stainless steel when subjected to adhesive wear loading. The weight loss (WL) and the specific wear rate (SWR) of the mild steel using each of the prepared lubricants were determined. Scanning electron microscopy was used to examine the worn surface of the mild steel. The results revealed that pure canola oil as a lubricant performed competitively against a blend of $80 \%$ synthetic and $20 \%$ canola oils. The viscosity of the canola oil and its various blends with synthetic oil are controlled by the environmental temperature since an increased temperature reduces the viscosity. Also, the experimental results revealed that operating parameters play the main role in controlling the wear behavior of mild steel since increasing the sliding distances increases the weight loss. The specific wear rate exhibited a steady state after about $5 \mathrm{~km}$ sliding distance, and different blends influenced the applied loads and velocity differently. The mixing ratio of canola and syntactic oil was not particularly significant since the pure canola oil exhibited competitive wear performance compared with the blends. However, an intermediate mixing ratio (40\%-60\% synthetic oil mixed with $60 \%-40 \%$ canola) can produce a slightly low specific wear rate among other things.
\end{abstract}

\section{Introduction}

Recently, major concerns have emerged over the increasing use of conventional fossil fuels in industrial products and applications. The use of vegetable oil, an important discovery, has been the focus of many contemporary technological and industrial researchers. Many studies have recently explored the possibility of using vegetable oil as a lubricant. The results are promising; vegetable oil has a good chance of being a better alternative to mineral oil both economically and environmentally [1-4]. In the contemporary world, biodiesel has continually received great attention as being an alternative biodegradable and nontoxic renewable source of fuel. Besides, in the industrial world, the attention has further been shifted with the potential use of this invention for lubrication. Initially, petroleum byproducts were the only ones used for lubrication [5]. This is, however, a thing for the past. The emergence of the use of vegetable oil has inspired the extension of this knowledge to the extent that recent discoveries show that it is a better alternative for conventional lubricants. Conventional lubricants having numerous advantages have their share of disadvantages [6]. The fact that conventional fossil fuel petroleum is in abundance is worth noting. However, this should not bling one to the fact that this fuel is exhaustible [7]. This introduces a new twist in the large-scale application of lubricants. Biodiesel, being the better alternative, continues to show unending promise as researchers invest millions of dollars to try and implement biodegradable alternatives. 
The application of vegetable oils for the lubrication of machinery has been applied for ages. However, much attention shifted the moment cheaper and more available alternatives were found [7]. This attention has since been refocussed due to the continued shrinkage of oil fields. Vegetable lubricants have been majorly motivated by the need to conserve the environment. The next decade is likely to experience the use of biodegradable greases and lubes than it has been in any moment of history. Great controversy has recently emerged on ways to involve vegetable oils in industry and manufacturing. Recent technological and engineering studies have pointed to the possibility of vegetable oil replacing fossil fuels, not just because of its numerous inherent advantages but also because it is environmentally friendly $[8,9]$. In today's world, biodiesel has always been paid much attention as an alternative biodegradable and nontoxic renewable source of fuel [7]. Moreover, the industry has also moved to consider the possible use of biodiesel for lubrication. Initially, petroleum by-products were the only sources of lubricants [5]. But it is very uncertain whether vegetable oils outdo conventional lubricants in all respects. Despite being a renewable source of lubricants and having the advantage in environmental conservation, their demerits cannot be overlooked. For example, it is challenging to modify these lubricants due to issues of viscosity and structural alteration. This is why researchers have investigated this vast field in the hope of improving green sources, given their promise as the next generation of lubricants in the field of tribology [10].

In current engineering technologies, especially mechanical engineering, sliding and rolling surfaces are among the most important topics to study. In designing machine elements, it is essential to understand the principles of tribology [11]. When two flat-looking surfaces are brought into contact, their surface roughness causes points on the two surfaces to make contact in different places, creating interfacial adhesion. Then, friction occurs when the two bodies try to move in relation to each other [12]. Due to these friction forces, one or both surfaces experience the wear or removal of material. If this continues for a long time, the dimensions of the mechanical parts are altered and the machine's functionality is reduced [13].

Industries and researchers are searching for alternative renewable sources of lubricants to be used in place of fossil oils. Biobased lubricants have many properties that give them an advantage over petro-based lubricants, but they still have some undesirable properties which make petro-based lubricants preferable for many applications. Research has been done to improve the quality of physical attributes and reduce the cost of using biobased lubricants so as to compete with petro-based lubricants [14]. There are now policies to improve the use of biobased lubricants, but the perception and allocation of land for this purpose still create problems. Countries cannot completely change from petro-based lubricants to biobased lubricants overnight. This must be a gradual process that requires support from the government, agriculture, research, and industry. Due to the rapid economic growth in Asia alone, the world demand for lubricants has greatly risen [15]. Nagendramma and Kaul [15] report that the demand for lubricants is predicted to increase by 1.6 percent annually for at least another three years beyond the current demand of 40 million tons. Even though the consumption is so high, only a small percentage is being recycled. So, the need arises to find a renewable alternative to satisfy the growing need. Biobased lubricants are of limited use, but they can be applied in several environmentally sensitive industries such as agricultural machines and other types of machinery used under or very close to water resources. The reasons for this are that they are nontoxic and create a very small disturbance to the ecosystem.

The biggest difficulty for research in the development of biolubricants is to enhance their physical characteristics without damaging their biodegradable, tribological, and environmental properties. Controlling behavior consists of the following aspects: control of their hydrolytic stability, their physicochemical characteristics, their environmental characteristics, their compatibility with materials and seals, the temperatures when they are used, and their oxidative stability [16]. Researchers have explored biodiesel tribological issues for close to three decades now. Seen from a quantitative point of view, the amount of metal gives the various engines their component of wear and tear. The quantitative analysis tries to give a likely source of the metals. The lubricity issue is central. The introduction of low sulfur diesel fuels by regulators in countries such as the United States has led to the failure of several engine parts such as injectors [17]. This is because the pumps and the injectors are lubricated by the same fuel.

In comparison to fossil fuels, the primary problem with biodiesel is the concern about viscosity [17]. Viscosity is not affected, and any effort to modify tribological compound viscosity leads to substantial changes in lubricant structure and effectiveness. These lubricants are sensitive in that any small change in structure affects and reduces the effectiveness of these substances. It is proved that it is very difficult to make the tribological compounds more useful while avoiding any alteration in their structure [18] because the balance between these outcomes is delicate.

Vegetable oil types are numerous, and canola oil is one of the most important types. It is available all around the world and it is not expensive. In Canada today, canola oil is the third most important product [19]. It can be blended with other oils, which makes it one of the best lubricants. Canola oil is rich in oleic and linolenic acids which lead to a healthier life.

Canola oil is considered a very healthy oil due to its fatty acid composition. It averages about $60 \%$ oleic acid (C18:1), 20\% linoleic acid (C18:2), and 10\% ALA (C18:3) [20]. Canola oil is extracted from the seeds of the canola plant. This plant was developed by plant breeders from the rapeseed oil plant since rapeseed oil was risky for human and animal health [21] because of its high proportion of erucic acid. A significant quantity is present in the animal feed made from rapeseed oil, known to inhibit animal growth rates when taken with high quantities of glucosinolates. Hence, plant breeders embarked on the development of rapeseed plant types with a low content of erucic acid, low erucic acid rapeseed (LEAR), and also low in glucosinolate 
[22]. For marketing purposes, rapeseed plant breeders in Canada named LEAR 'canola'. With its low levels of erucic acid, glucosinolate, and saturated fats, LEAR (canola oil) appealed to health-conscious consumers and increased the demand for it. The production of canola oil has increased dramatically since World War II.

Canola is also utilized in industry to produce biodiesel, a type of biofuel used for automotive engines. Besides being used to produce biodiesel [23], canola oil was also utilized to create a range of consumer and industrial goods, including lubricants, due to its nontoxicity [23].

\section{Methodology}

2.1. Selection and Preparation of Materials. In this study, different blends of vegetable oil were mixed with fully synthetic oil. The blend consisted of different proportions, e.g., $20 \%, 40 \%, 60 \%$, and $80 \%$ of synthetic oil supplemented as necessary by vegetable oil. In this work, canola oil and fully synthetic Castrol oil for two-stroke engines represent the vegetable oil and the synthetic oil, respectively (see Table 1). The specifications of the selected canola oil and fully synthetic oil are given in Tables 2 and 3 .

To get a homogeneous mixture of lubricants, the synthetic oil had to be poured properly on the vegetable oil, which was heated to $50^{\circ} \mathrm{C}$. An electrical mixer at a very low speed was also employed to achieve a good blend.

2.2. Tribology Machine and Experimental Procedure. In this study, the wear characteristics of mild steel samples were examined under ambient conditions (humidity $=50 \% \pm 5$, temperature $=25^{\circ} \mathrm{C}$ ) and wet contact against a stainless steel counterface (AISI 304, Ra ("roughness average") = $0.1 \mu \mathrm{m}$, hardness $=1250 \mathrm{HB}$ ). The tribological characteristics of the samples were studied applying the BOR ("block on ring") method, with a newly built machine designed to handle this technique as shown in Figure 1 [26]. The most essential components of the tribology machine are the container filled with the various mixes and the arm attached to the container that provides the load for the samples. A sliding distance of $0-10 \mathrm{~km}$, sliding speed of $(0-2 \mathrm{~m} / \mathrm{s})$, and the applied load of (10 to $20 \mathrm{~N}$ ) were maintained in the experiments.

Three samples for each set were tested, and the average for each set was determined and the load cell was calibrated. It should be mentioned here that several attempts have been adopted to get the precise procedure. The samples were weighed, dried, and cleaned prior to the operation of the machine. The specimens were then mounted on the machine holder, the timer, and the load cell reader set to zero before testing at the necessary load distance. The samples were weighed, dried, and cleaned after the test. The variation in sample weight was calculated. The loss of wear volume was determined employing a weighing scale of $\pm 0.1 \mathrm{mg}$ as a result of the WL of each sample. Equation (1) was used to determine SWR. The average measurement of each dilution of canola oil was determined three times for each test.

$$
\operatorname{SWR}=\frac{\Delta w / \rho}{L \times D},
$$

where $\Delta$ weight $=$ weight (before) - weight (after), $\rho$ is the sample density, $L$ is the applied load, and $D$ is the sliding distance.

The prepared mixture's viscosity was calculated using a "Viscometer" in the "University of Southern Queensland". Several oil temperatures were taken into account $\left(10^{\circ} \mathrm{C}-80^{\circ} \mathrm{C}\right)$. "Scanning electron microscopy" was employed to analyze the worn surfaces of the samples of mild steel. This microscopy is labeled as "Joel" which belongs to the "University of Southern Queensland".

\section{Results and Discussion}

In this section, the results will be addressed of testing the viscosity of different blends at different temperatures, the wear data from tribological applications, and the surface characteristics of mild steel treated with tested with different blends and applications. Each parameter and its effect on aspects such as the surface and wear of mild steel are discussed hereinafter.

3.1. Blends' Viscosities. The viscosity results of the prepared blends at different temperatures as measured with a Viscometer are shown in Table 4. The results show the relationship between the temperature in ${ }^{\circ} \mathrm{C}$ and Viscosity in $\mathrm{Cp} \approx \mathrm{MPa}$ for four blends after applying heat from $10^{\circ} \mathrm{C}$ to $80^{\circ} \mathrm{C}$.

Table 4 reveals that the viscosity of all the blends significantly depends on temperature. In other words, the results state that viscosity is reduced as temperatures increase. The table demonstrates that the rise in the synthetic percentage also rises the viscosity. The additive synthetic appears to stabilize and increase the viscosity in the prepared mixture because of the presence of the lubrication additives. This rise in viscosity with the adding of synthetic oil may be because of the fact that the synthetic oils include additives like EVA which may substantially enhance viscosity, as stated by Quinchia et al. [27].

\subsection{Wear Behavior of Mild Steel Lubricated by Pure Canola} Oil. Figure 2(a) displays the WL in samples from mild steel to sliding distances when lubricated by pure vegetable oil. The figure illustrates that any rise in the sliding distance rises the WL. This phenomenon may be described by the fact that the rise in the sliding distance rises the material elimination from the soft rubbing port surface which in this case is mild steel. This result has been demonstrated by many articles such as $[28,29]$. The sliding distance linearly increases the $\mathrm{WL}$, as is well known, given the process of integration and adoption between the rubbed surfaces, [30]. To explain this further, the wear data are signified by a different type of wear, the SWR against the sliding distance. The SWR indicates the volume loss by the materials in terms of applied sliding distance and load. This can help to clarify the use of sliding surfaces when the rubbing time or the sliding 
TABLe 1: Blend oil percentage.

\begin{tabular}{lcc}
\hline Blend & Percentage of canola & Percentage of fully synthetic Castrol oil \\
\hline 1 & 100 & 0 \\
2 & 80 & 20 \\
3 & 60 & 40 \\
4 & 40 & 60 \\
5 & 20 & 80 \\
\hline
\end{tabular}

TABLe 2: Canola oil specification [24].

\begin{tabular}{lc}
\hline Parameter & Value \\
\hline Relative density $\left(\mathrm{g} / \mathrm{cm}^{3} ; 20^{\circ} \mathrm{C} /\right.$ water at $\left.20^{\circ} \mathrm{C}\right)$ & $0.914-0.917$ \\
Cold test $\left(15\right.$ hours at $\left.4^{\circ} \mathrm{C}\right)$ & Passed \\
Thermal conductivity $\left(\mathrm{W} / \mathrm{m}^{\circ} \mathrm{K}\right)$ & $0.179-0.188$ \\
Refractive index $\left(\mathrm{nD} 40^{\circ} \mathrm{C}\right)$ & $1.465-1.467$ \\
Smoke point $\left({ }^{\circ} \mathrm{C}\right)$ & $220-230$ \\
Viscosity $\left(\right.$ kinematic at $\left.20^{\circ} \mathrm{C}, \mathrm{mm}^{2} / \mathrm{sec}\right)$ & 78.2 \\
Specific heat $\left(\mathrm{J} / \mathrm{g}\right.$ at $\left.20^{\circ} \mathrm{C}\right)$ & $1.910-1.916$ \\
Crismer value & $67-70$ \\
Flash point, open cup $\left({ }^{\circ} \mathrm{C}\right)$ & $275-290^{\prime \prime}$ \\
\hline
\end{tabular}

TABLE 3: Fully synthetic oil specification [25].

\begin{tabular}{lc}
\hline Colour & Deep red \\
Base number & 2.5 \\
Sulfated ash, mass\% & $<0.10$ \\
Flash point & 94 \\
Biodegradability, OECD 301B, \% & 64 \\
Viscosity index & 175 \\
Density at $15^{\circ} \mathrm{C}, \mathrm{kg} / \mathrm{L}$ & 0.895 \\
Viscosity, kinematic, cSt & \\
$\quad$ At $40^{\circ} \mathrm{C}$ & 39 \\
At $100^{\circ} \mathrm{C}$ & 7.8 \\
\hline
\end{tabular}

distance rises. Figure 2(b) shows the SWR against the sliding distance of mild steel lubricated by pure vegetable oil. The SWR begins at a high level and subsequently declines. However, as the sliding distances increase, the decline in the SWR value is not so marked. A technique is carried out during the initial step of the rubbing process. In other terms, the two surfaces are adopting one another for greater surface integration. With further sliding (over $5 \mathrm{~km}$ ), the SWR is steadily lower which represents the steady state of the rubbing procedure. In other terms, the material elimination remains constant corresponding to the sliding distance. It must be noted that the "steady state" of the specified wear rate is the value that the designer takes into account in the production of components. This is a frequent trend in metals and polymers because the interface or rubbed surfaces are not very much modified while sliding. This behavior by two different types of steel has recently been reported [31, 32].

The SWR of mild steel versus sliding velocity is created and shown in Figure 3(a) to illustrate the impact of a sliding speed on the wear performance of mild steel. This figure demonstrates that the SWR against the counterface speed of mild steel lubricated with pure vegetable oil is high when the velocity is at a low level.

From the viscosity data presented in Table 4, it seems that the pure canola oil velocity is low. In other terms, during the sliding, not enough is being lifted to the surfaces. At high speed, however, pure canola oil may separate the mild stainless steel from the stainless steel counterface at a certain level, resulting in poor material removal.

To show the influence of the sliding speed on the wear behavior of the mild steel, the specific wear rate of the mild steel against sliding velocity is generated and plotted in Figure 3(a). In Figure 3(a), the specific wear rate against the speed of the counterface on mild steel under the pure vegetable oil lubricant condition shows that the specific wear rate is high at the level of low velocity. From the viscosity data presented in Table 4, the velocity of the pure canola oil is low. In other words, there is not enough lifting to the surfaces during the sliding. However, at high speeds, the pure canola oil can separate the mild steel from the stainless steel counterface at a certain level which resulted in low removal of materials.

The influence of the applied load lubricated by pure vegetable oil on the SWR is demonstrated in Figure 3(b). This figure shows that the SWR decreases with a load increase from $100 \mathrm{~N}$ to $140 \mathrm{~N}$ and then increases with an intermediate load value of $180 \mathrm{~N}$ and then a sudden drop with a very high load of $200 \mathrm{~N}$. The rise in applied load must be indicated here as a proportional relationship of the weight loss to the material removed. However, it is extremely difficult to connect this with the relationship between the SWR as well as the applied load. These scattered measurements of the SWR were prevented by numerous writers, who present the data in terms of WL (such as [33]), or volume loss (such as [34]). In contrast, Chin and Yousif [35] have found comparable scattered values of SWR when testing polymeric composites against stainless steel under various applied loads. From this evidence, the findings of the tests in the present research agree with those in the current literature.

3.3. Wear Behavior of Mild Steel Lubricated by 20\% of Synthetic Oil and $80 \%$ of Canola Oil. This section is identical to the above except that the lubricant properties could be expected to be different because the findings in this section are produced by a mixture condition of $80 \%$ of canola oil and $20 \%$ of synthetic oil. The findings are given in the same way as those of the previous section. In other terms, wear test results are studied under various operating conditions. With respect to the loss in weight versus the sliding distance, Figure 4(a) illustrates the WL versus sliding distance on mild steel lubricated with a mixture of $80 \%$ of canola vegetable oil and $20 \%$ of synthetic oil. The WL trend is like the trend shown by the pure canola oil as a lubricant because an 

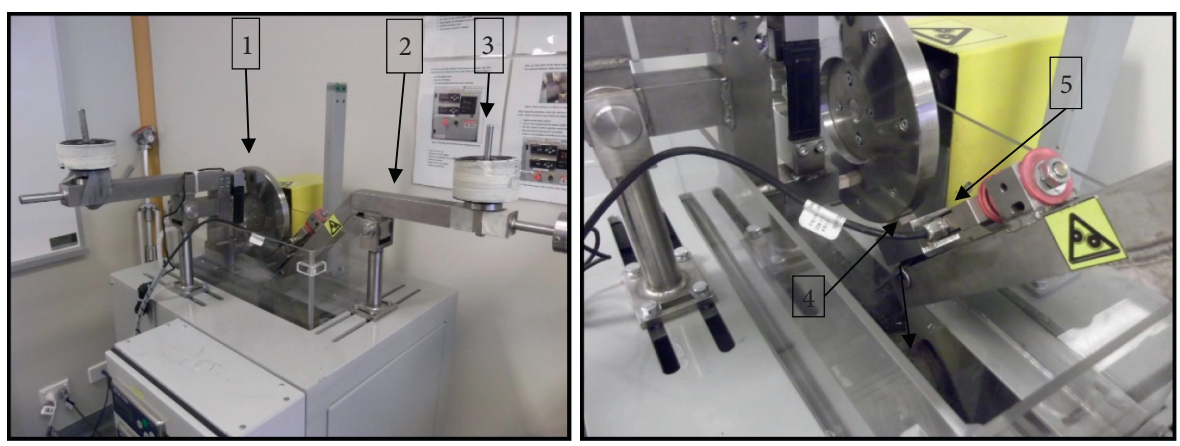

FIgURE 1: The Tribo-test machine. $1=$ counterface, $2=$ BOR-load lever, $3=$ dead weights, $4=$ BOR-specimen, and $5=$ BOR-load cell.

TABLE 4: Viscosity findings for different percentage blends at various temperatures.

\begin{tabular}{lcccc}
\hline Temperature $\left({ }^{\circ} \mathrm{C}\right)$ & $80 \% \mathrm{SNO}+20 \% \mathrm{VGO}(\mathrm{mPas})$ & $60 \% \mathrm{SNO}+40 \% \mathrm{VGO}(\mathrm{mPas})$ & $40 \% \mathrm{SNO}+60 \% \mathrm{VGO}(\mathrm{mPas})$ & $\begin{array}{c}20 \% \mathrm{SNO}+80 \% \mathrm{VGO} \\
(\mathrm{mPas})\end{array}$ \\
\hline 10 & 185.2 & 177.4 & 170 & 121 \\
20 & 145.5 & 132.9 & 92 & 111 \\
25 & 120.4 & 106.6 & 81.5 & 85 \\
30 & 96 & 87.3 & 56.8 & 72 \\
40 & 65 & 60.9 & 40.6 & 52.5 \\
50 & 49 & 44.6 & 30.5 & 26.6 \\
60 & 37.8 & 32.7 & 23.8 & 28 \\
70 & 30.6 & 27.6 & 17.6 & 14.8 \\
80 & 23.8 & 20.5 & \\
\hline
\end{tabular}

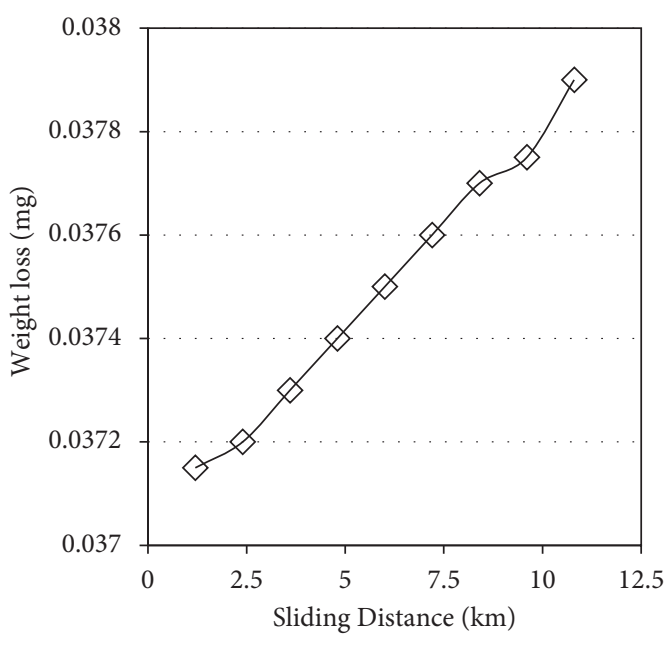

(a)

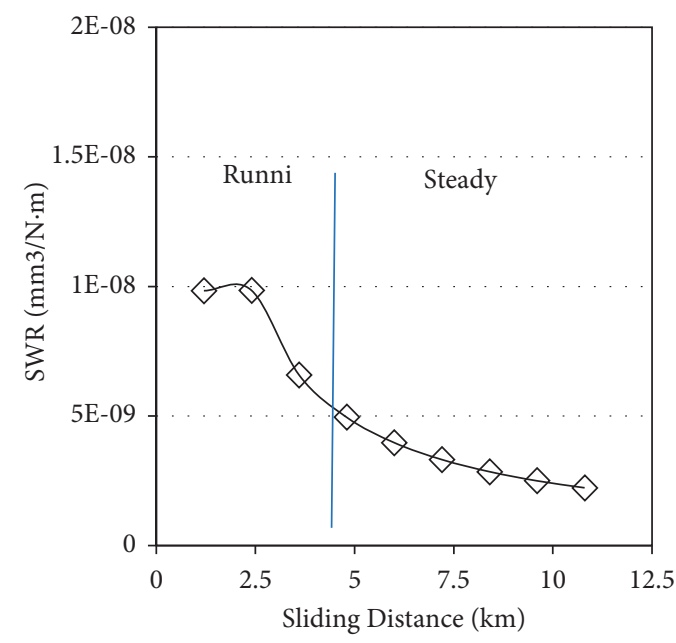

(b)

FIgURE 2: (a) Weight loss and (b) SWR versus sliding distance of mild steel lubricated by pure vegetable oil.

increase in sliding distance raises the accumulated WL in the preceding section (see Figure 3(a)). This is fully described in the preceding section, where the removal of material is in a proportional ratio to the sliding distance and is explained and approved in the literature. However, it would be noted here that the difference between this result and the preceding one is that the viscosity of the lubricant is greater now than before, which could have impacted the values of wear.
To display the SWR for the mild steel lubricated with 20 percent of synthetic oil mixed with 80 percent of canola in connection with the sliding distance, Figure $4(\mathrm{~b})$ is plotted. The SWR rises with the rise of the sliding distance. This is not the typical depiction with sliding distances of the SWR. The typical pattern is a rise followed by a drop and then a steady state. It seems that the major problem to raise here is the low SWR on small sliding distances. This may be primarily 


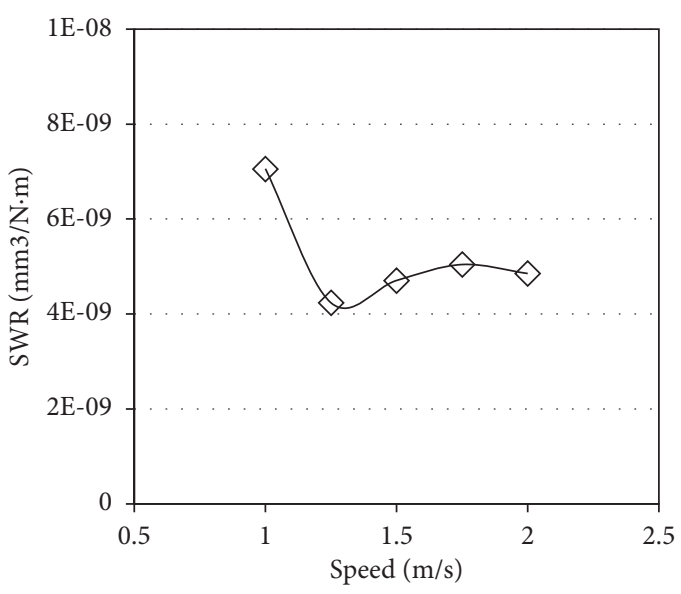

(a)

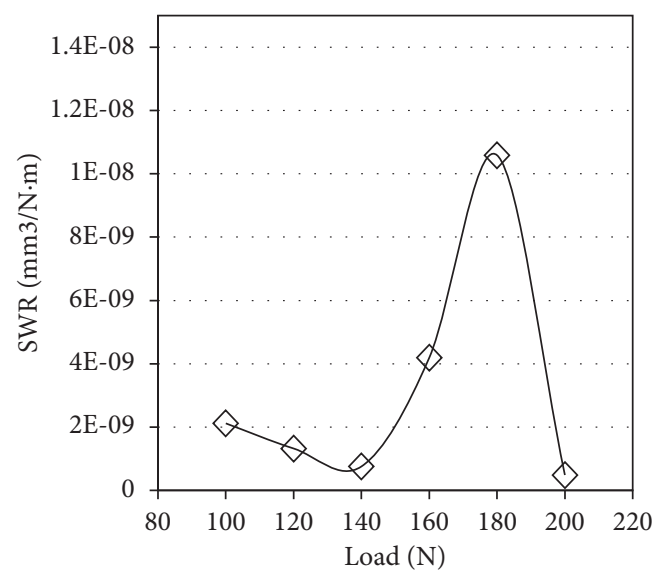

(b)

FigURE 3: SWR of mild steel lubricated by pure vegetable oil against (a) speed and (b) load.

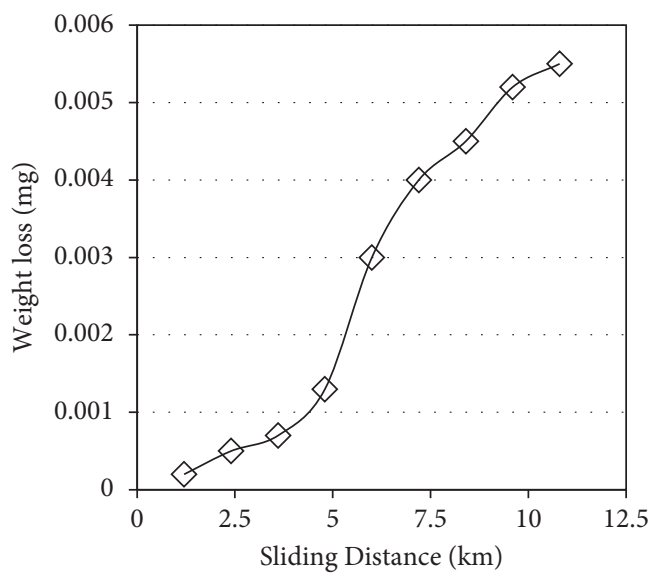

(a)

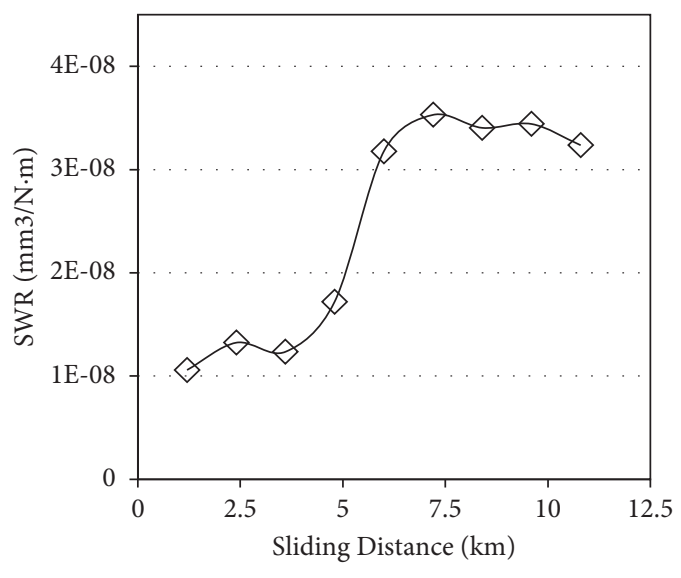

(b)

FIgURE 4: (a) Weight loss and (b) SWR of mild steel versus sliding distance lubricated by a blend of $20 \%$ of synthetic oil and $80 \%$ of canola oil.

because of the greater viscosity of the mixtures as compared to pure canola, which indicates the common trend of the SWR in relation to sliding distance (Figure 3(b)). Nevertheless, the mild steel was coated with lubricant at the initial stage of the rubbing resulting in a drastic high reduction of the material removed. This action has been reported by Mat Tahir et al. [36] describing a PKAC-E ("palm kernel activated carbon-epoxy") composite tested at high temperature. In his study, he provided the presence in the interface of a third body as the cause for the rise in the SWR, and the same reason may also account for the present results.

Figure 5(a) indicates the impact of the sliding speed on the SWR of the mild steel lubricated by a 20 percent synthetic mixture. As with the previous data concerning pure canola oil (Figure 3(a)), a drop in the SWR is shown with every rise of the velocity. The primary reason is that more lubricant is on the interface at a higher speed.

In the preceding section, the applied load influence on the SWR was not significant, as the data were scattered
(Figure 3(b)). The SWR versus the load applied to mild steels lubricated by a blend of a 20 percent $\mathrm{SN}$ as well as pure canola oil reveals the same trend as the previous one as in Figure 5(b). The discussion in the last part is identical to the one given here. Despite these variations in the data, the changes in the SWR are very small, a power of $10^{-8}$. In a component design, it could be stated that no effect can be traced on the mild steel wear performance on the applied load because this is not a noticeable change in SWR values [37].

3.4. Wear Behavior of Mild Steel Lubricated by $40 \%$ of Synthetic Oil and $60 \%$ of Canola oil. This section discusses the wear behavior of mild steel with a $40 \%$ synthetic oil mixture in a lubrication state. Figure 6(a) shows the materials removed during the rubbing process from the mild steel when lubricated by a blend of 40 percent of synthetic oil over a sliding distance. Similarly, to previous linked sections, the 


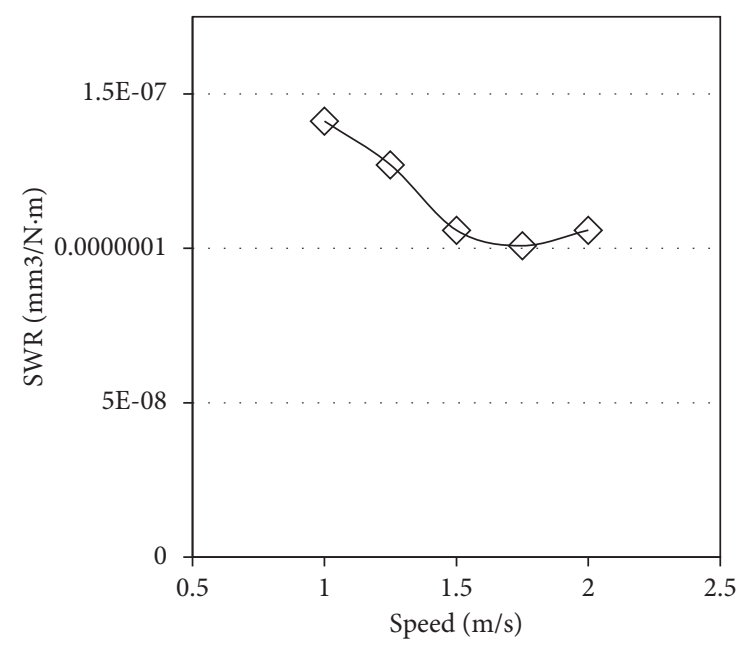

(a)

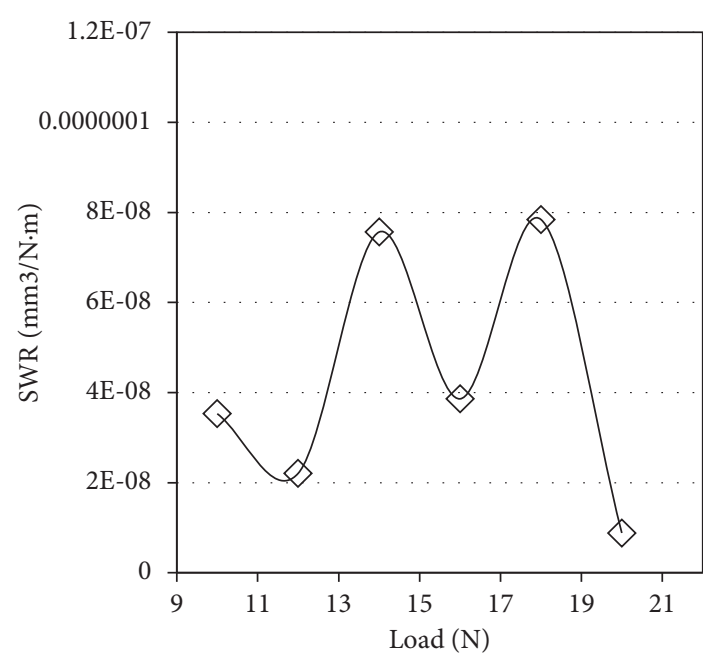

(b)

Figure 5: SWR of mild steel lubricated by a blend of $20 \%$ of synthetic oil and $80 \%$ of canola oil against (a) speed and (b) load.

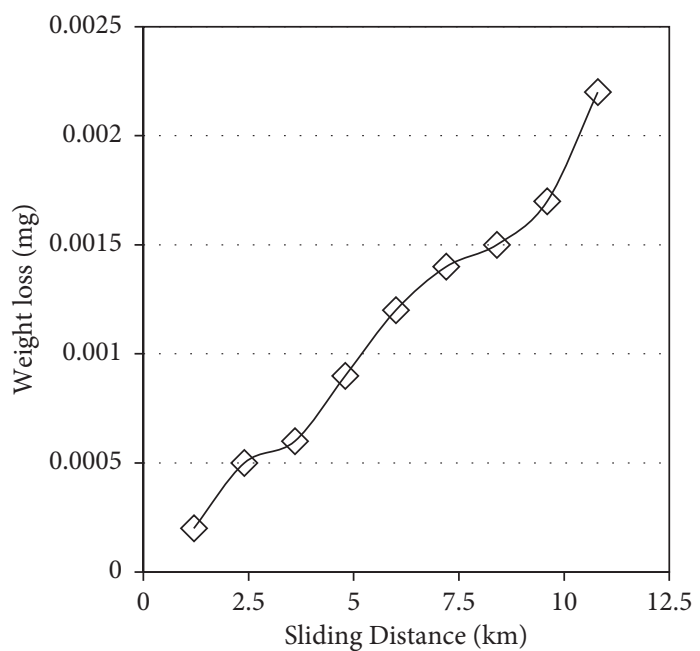

(a)

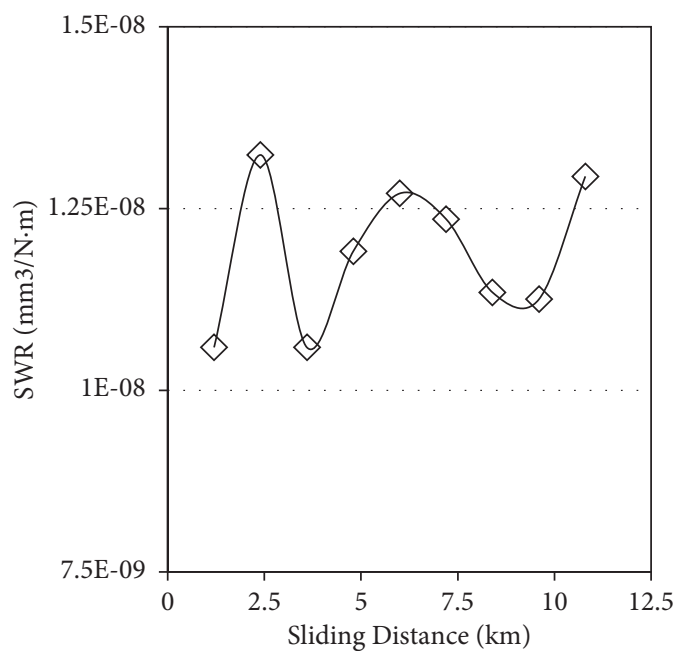

(b)

Figure 6: (a) Weight loss and (b) SWR of mild steel versus sliding distance lubricated by a blend of $40 \%$ synthetic oil and $60 \%$ canola oil.

weight loss of mild steel rises with a rise in the sliding distance owing to the first removal from the surface of the material, when pure canola (Figure 2(a)) and a synthetic oil mixture of 20 percent were used (Figure 4(a)). It should be noted here that the rubbed surfaces in the early stage have tips that may be eliminated (high loss in weight) easily and that sometimes the surfaces undergo pure adhesive wear. Scherge and Linsler [38] thoroughly discussed and described this step in the testing under lubricant contact circumstances of various metal-metal contacts. However, in that study, the primary emphasis was on the run-in stage, which may provide a similar interpretation in relation to the friction coefficient.

Figure 6(b) displays the SWR against the sliding distance of mild steel lubricated by a 40 percent $\mathrm{SN}$ as well as pure vegetable oil blended. The figure indicates variations in the
SWR value; however, it must be noted that variation in terms of value is extremely small, as the range of the SWR is approximately $\pm 0.2510^{-8}$. As already stated in Section 3.3, this quantity can safely be ignored in the design of the component. In other words, it can be said that the sliding distance has a very minor influence on the SWR of the mild steel. This may be because of the increased proportion of synthetic oil compared to the blend in earlier sections. Some additives such as EVA serve as coating agents in synthetic oil to inhibit material removal.

Figure 7(a) introduces the SWR against the counterface sliding speed on mild steel lubricated by a $40 \%$ percent synthetic oil mixture. The SWR starts high and then decreases. Generally, the figure indicates that the rise of the sliding velocity leads to a decrease in SWR. The trends in the SWR in the connection to velocity are similar 


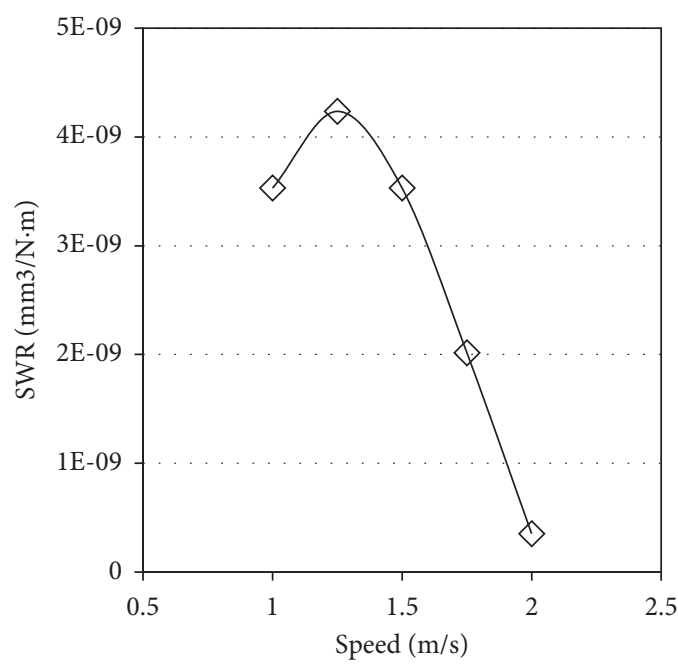

(a)

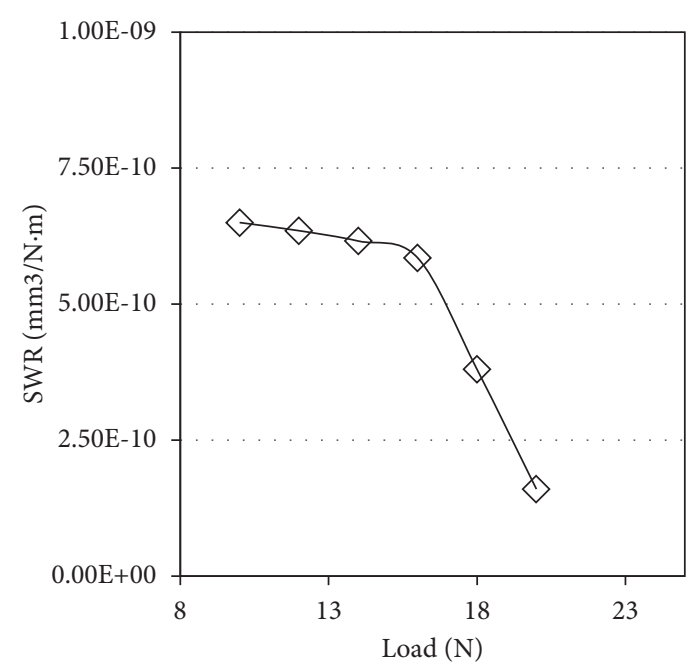

(b)

FIgURE 7: SWR of mild steel lubricated by a $40 \%$ synthetic and $60 \%$ canola oil blend against (a) speed and (b) load.

to those shown in this section in the 40 percent synthetic oil mixture in Figures 3(a) and 5(a) for pure canola and synthetic oil mixture lubricants of $20 \%$. Likewise, the rise in velocity encourages the lubricant to flow over the interface where the lubricant acts as a separating agent. Yet, very small amounts of materials are removed, amounting to $10^{-9}$ value. Figure $7(\mathrm{~b})$ presents the SWR versus the load applied on the mild steel lubricated by a 40 percent synthetic oil mixture. The SWR begins to be high and then drops to a low level. However, when we determine the weight loss only, a rise in the applied load rises the removal of materials. The SWR is reduced in terms of material removal in relation to the applied load values. The drop value is approximately $10^{-10} \mathrm{~mm}^{3} / \mathrm{N} . \mathrm{m}$.

\subsection{Wear Behavior of Mild Steel Lubricated by a $60 \%$ Synthetic} Oil and 40\% Canola Oil Blend. Figure 8(a) illustrates the sliding distance versus weight loss on mild steel lubricated by 60 percent synthetic oil mixed with 40 percent canola oil. Essentially, the increase in the sliding distance results in an increased WL. The linear relationship between WL and the sliding distance is evident in this figure, which resembles those exhibited before involving pure canola, a 20 percent synthetic mixture, and a 40 percent synthetic mixture. The reason for this behavior is discussed in depth in previous sections.

Figure 8(b) shows the SWR versus the sliding distance of mild steel lubricated with 40 percent pure vegetable oil and 60 percent SN blend. The SWR starts at high and then maintains a steady state. This behavior is common of all the substances that manifest high material eliminated in the $1^{\text {st }}$ phase, the running-in interval, by following a steady state that presents the efficiency of the mild steel for long periods when lubricated by this blend. From this figure, the SWR of the mild steel is equivalent to 3 $10^{-9} \mathrm{~mm}^{3} / \mathrm{N} . \mathrm{m}$ at the steady stage after approximately $5 \mathrm{~km}$ sliding distance or more.
Figure 9(a) introduces the SWR versus the velocity of the counterface on mild steel lubricated by a 60 percent synthetic oil mixed with $40 \%$ canola oil. The SWR is fluctuating. In comparison to previous findings for pure canola, 20 percent synthetic, and 40 percent synthetic lubricants, the 60 percent of synthetic oil illustrates an unremarkable impact on the SWR of the mild steel with respect to velocity. This may be caused due to a variety of factors, like the dirt thickness, lubricant adherence to the surface, or debris washing on the interface. On the basis of the available data, the high viscosity of this mixture is the main cause contrasted with the low proportion of syntactic oil in other mixtures. The high-velocity oil enters the interface and performs an important role in cooling down the area carrying the debris or/and spreading it over the surface.

Figure 9(b) presents the SWR against the load applied on the mild steel lubricated by 60 percent synthetic oil. Like the preceding trends in pure canola, the applied load for this combination is 20 percent of synthetic oil and 40 percent of synthetic oil.

3.6. Wear Behavior of Mild Steel Lubricated by $80 \%$ of Synthetic Oil and 20\% of Canola Oil. The wear findings of the mild steel sliding versus the counterface of the stainless steel lubricated by 80 percent synthetic oil mixed with 20 percent canola oil are shown in Figures 10 and 11 in various operating conditions. In regard to weight loss, Figure 10(a) displays the WL versus sliding distance on mild steel lubricated by an 80 percent synthetic oil mixture. Generally, the increase of sliding distance leads the weight loss to rise. This is a trend similar to those demonstrated before when various mixtures were employed; the rise in $\mathrm{WL}$ is a wellknown phenomenon.

Regarding the sliding distance effect on the SWR, Figure 10(b) shows the SWR versus the mild steel sliding distance lubricated by an 80 percent synthetic mixture. The SWR range may be observed at approximately 8 


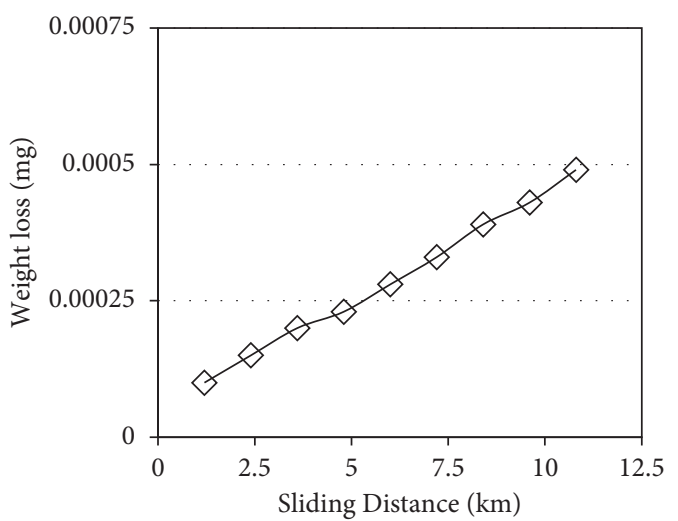

(a)

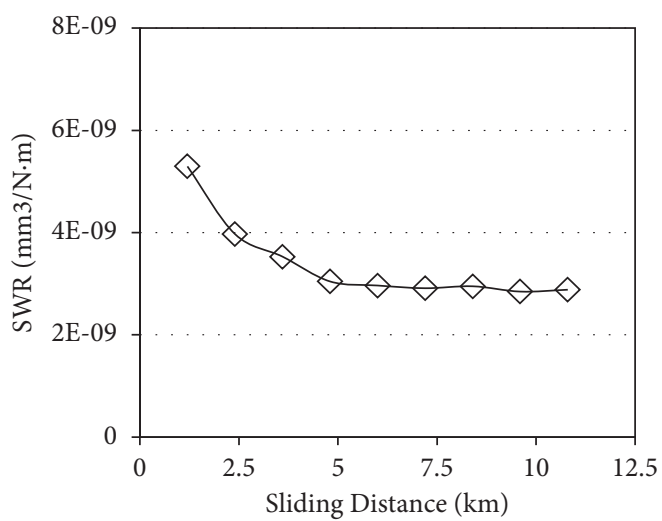

(b)

FIGURE 8: (a) Weight loss and (b) SWR of mild steel against sliding distance lubricated by the $60 \%$ synthetic and $40 \%$ canola oil blend.

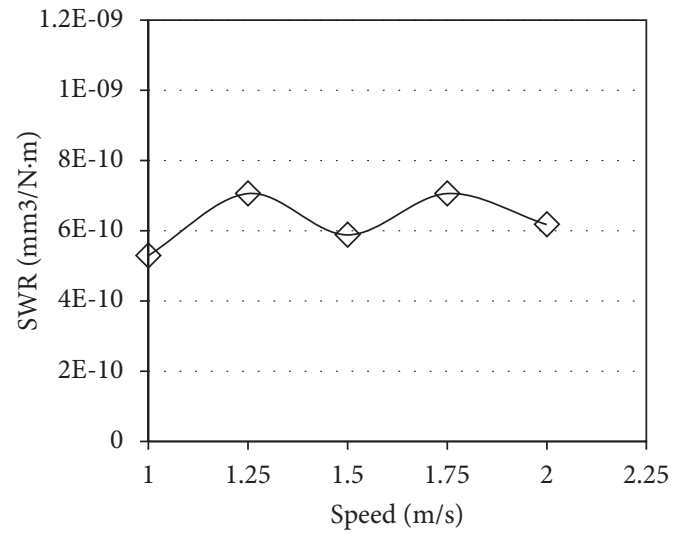

(a)

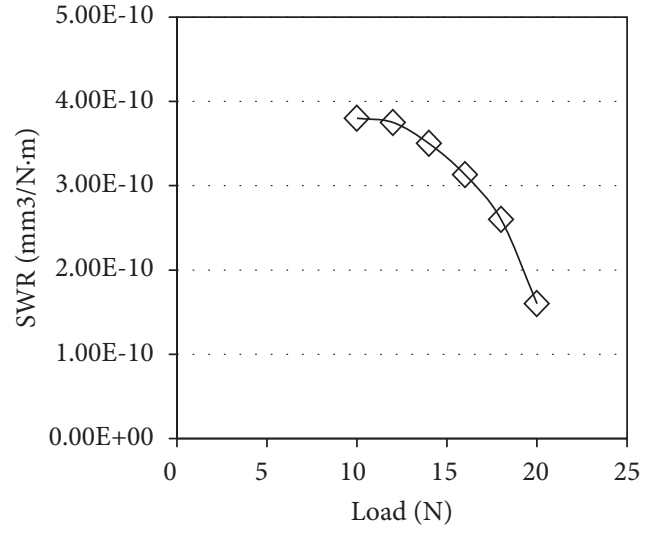

(b)

FIgURE 9: SWR of mild steel lubricated by $60 \%$ synthetic and $40 \%$ canola oil blended against (a) speed and (b) load.

$10^{-8} \mathrm{~mm}^{3} / \mathrm{N} . \mathrm{m}$. The change in the SWR is in a range of \pm 2 $10^{-8} \mathrm{~mm}^{3} / \mathrm{N}$.m. The substantial effect of the sliding distance on SWR cannot be seen. It may be suggested that the cause for this is the high viscosity of the blend, which consists of $80 \%$ synthetic oil, introducing a higher viscosity than any previous blend. At their high viscosity, the ability to separate mild steel and stainless steel on two rubbed surfaces is greater than separating those at the low-viscosity surfaces.

Figure 11(a) represents the SWR versus the counterface sliding velocity on mild steel lubricated by $80 \%$ of synthetic oil blended with 20 percent of canola oil. Generally, it may be observed from this figure that a rise in velocity increases the SWR. It was noted that the lubricant utilized to gain this result is highly viscose. The high viscosity related to high interface speed may exert an adverse effect on the material's wear rate $[39,40]$.

Figure 11(b) shows the SWR versus load applied to mild steel lubricated by the 80 percent synthetic oil mixture. The rise in the applied load displays a reduction in the SWR; this behavior was shown earlier by mild steel under the conditions imposed by other mixtures. The cause for this is described above.
3.7. Influence of Synthetic Oil on Wear Behavior of the MS. To display the" impact of various mixtures on the SWR of the mild steel due to an optimized "mixing ratio", the SWR versus the mild steel sliding distance lubricated by all kinds of mixtures is shown in Figure 12. It may be said that the findings for all the blends here are comparable. The pure canola vegetable oil displays intermediate behavior compared to synthetic oil, particularly under steady-state conditions. The combination of the two oils appears to have distinct effects as the low synthetic oil percentage substantially improves the lubricant characteristics of the oil, resulting in the lowest SWR of all. But adding a high percentage of synthetic oil worsens the lubricant characteristics that indicated a high removal of materials from the mild steel.

3.8. Scanning Electron Microscopy Observations. Figures 13-15 show the surface morphology of the surfaces worn with mild steel. They were tested using various lubricants at $2 \mathrm{~m} / \mathrm{s}$ sliding velocities, $10 \mathrm{~km}$ sliding distance, and $20 \mathrm{~N}$ applied load.

In the condition of pure canola oil lubricant (Figure 13(a)), pure adhesive wear seems to be a smooth 


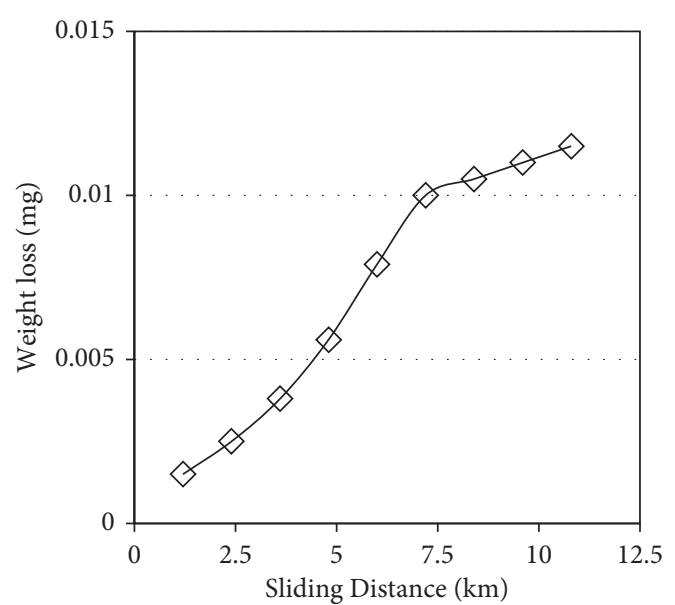

(a)

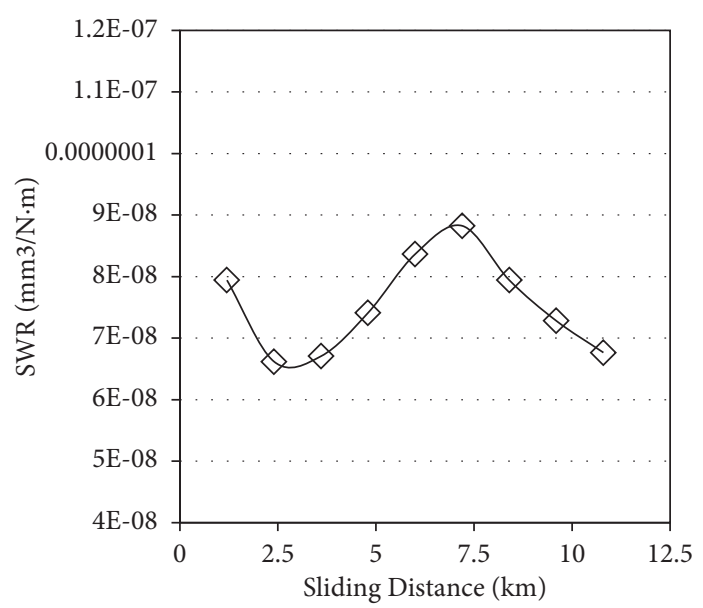

(b)

FIGURE 10: (a) Weight loss and (b) SWR of mild steel against sliding distance lubricated by the $80 \%$ synthetic and $20 \%$ canola oil blend.

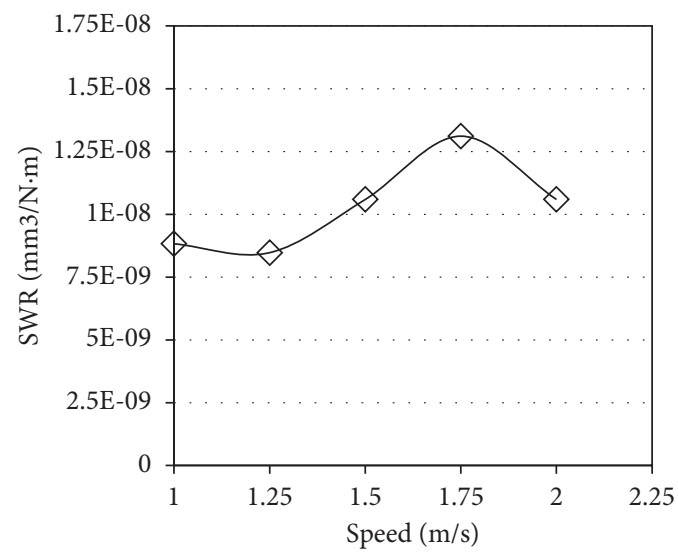

(a)

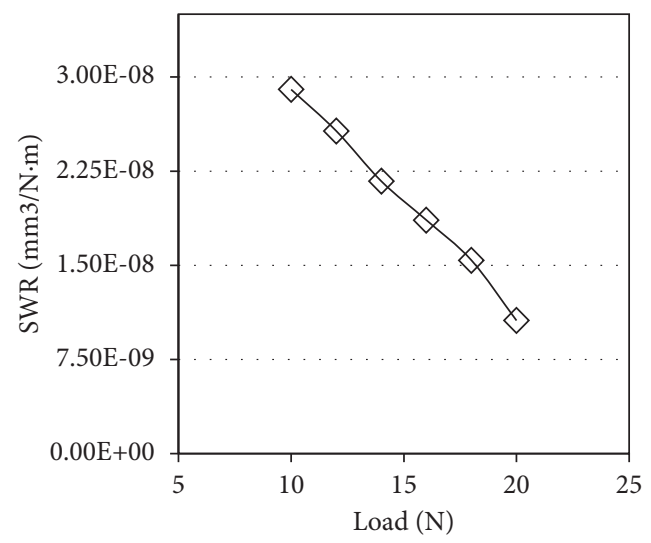

(b)

FIGURE 11: SWR of mild steel lubricated by an $80 \%$ synthetic and $20 \%$ canola oil blend against (a) speed and (b) load.

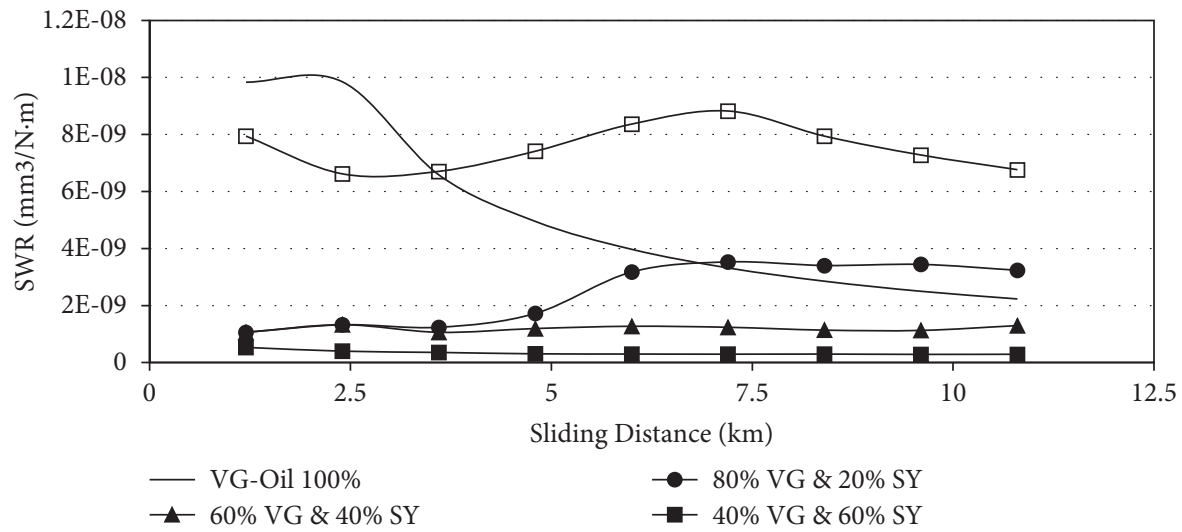

FIGURE 12: SWR behavior versus sliding distance for the effect of different blends on the mild steel.

surface. This shows the removal of few materials from the mild steel surface, which supports the findings provided in Figure 12. Low-viscosity oil may assist in heat reduction in the interface and debris washing $[41,42]$. On the other hand,
Figure 13(b) displays the 20 percent synthetic oil mixed with 80 percent canola utilized as the lubricant is an indication of the abrasive nature of the mild steel surface. This may encourage the concept that increasing the viscosity of the 


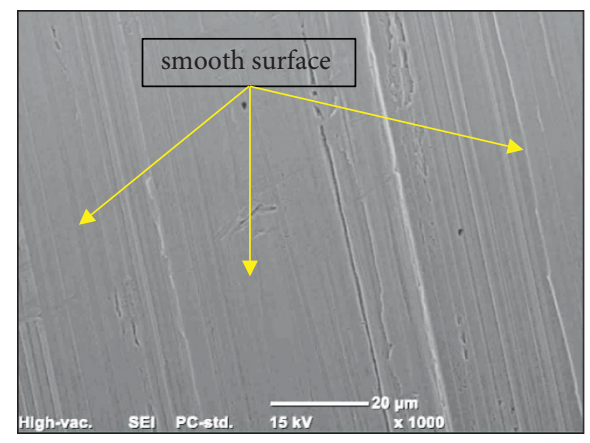

(a)

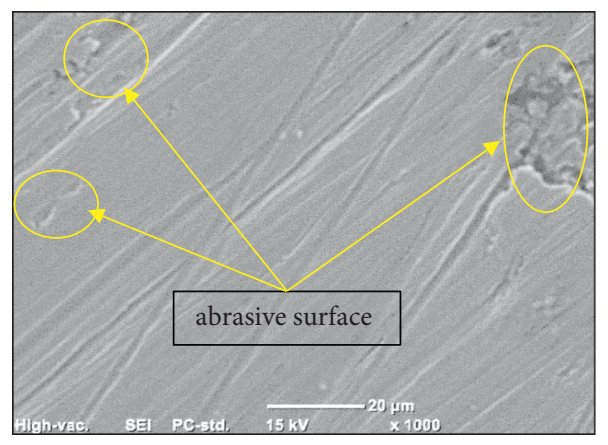

(b)

Figure 13: (a) Pure canola oil lubricant and (b) 20\% synthetic oil mixed with $80 \%$ canola oil.

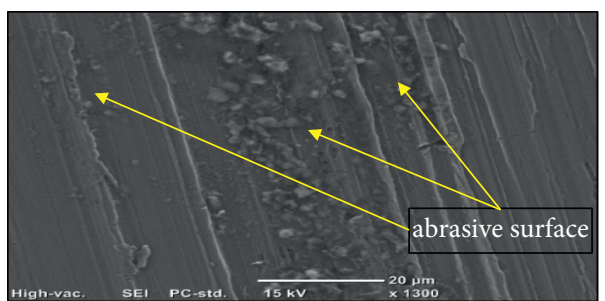

FIgURE 14: $40 \%$ synthetic oil mixed with $60 \%$ canola oil.

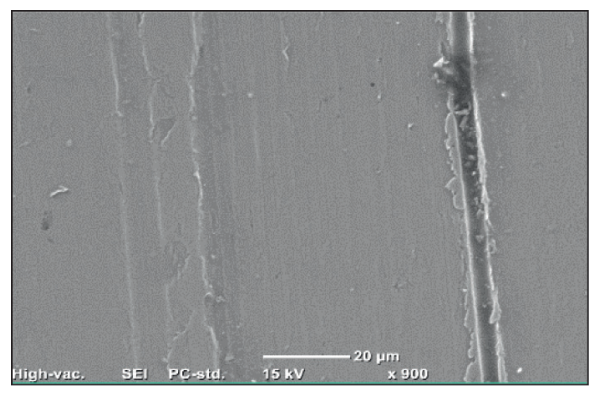

(a)

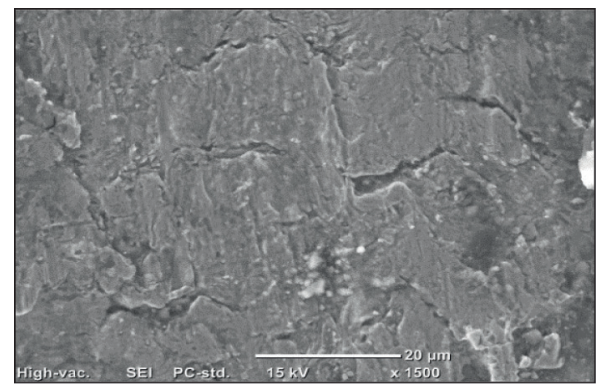

(b)

Figure 15: (a) 60\% synthetic oil mixed with $40 \%$ canola oil and (b) $80 \%$ synthetic oil blended with $20 \%$ canola oil.

lubricant allows the debris to be carried away and enters the interface by adding the synthetic oil. In other terms, the adhesive wear transfers into an abrasive surface.

Figure 14 exhibits the surface morphology of the worn surface of mild steel lubricated by $40 \%$ synthetic oil and $60 \%$ canola oil. Figure 14 shows further abrasiveness similar to what appears in Figure 13(a). As a higher viscosity lubricant was utilized to create the worn surface in this figure, it verifies the concept of high viscosity removing debris and therefore converting adhesive wear into abrasive surfaces leading to the removal of the plentiful material (Figure 12).
Figures 15(a) and 15(b) show the severely abrasive surface and the mild steel degradation, supposed to be caused by the three abrasive characteristics.

\section{Conclusions}

The primary aim of this work was to analyze the canola oil viscosity and its mixtures with various totally synthetic oil ratios and to examine the effect of those developed mixtures on the wear behavior of mild steel, rubbed against the counterface of stainless steel. The findings showed a 
relatively low viscosity of canola oil compared to oils previously examined in the literature like cotton, soy, and palm. However, this may be advantageous for some uses of lowviscosity canola oil, like bushes, slides, and bearings. Some particular results of this study may be discovered in the following points.

Table 4 evidently shows that the viscosity of all the blends together relies upon temperature; that is, the outcomes reveal that viscosity is diminished as the temperature rises.

(1) Mixing canola oil with synthetic oil enhances the lubricant's viscosity, thus improving its properties under certain circumstances. The lubricant is capable of spreading the two rubbed surfaces using a lubricant layer with high viscosity. However, high viscosity oil may carry away the worn debris, and this debris may enter the interface and create three-body abrasion, leading to the removal of such material

(2) For the tribological findings, the operating conditions have the fundamental charge of regulating the wear performance of the mild steel lubricated by all kinds of blends. Increasing the sliding distances increases the WL in all working conditions and mixtures of the mild steel. However, for most of the operating conditions, the SWR achieved a steady state after approximately $5 \mathrm{~km}$ sliding distance

(3) Regarding the effect of the mixtures on the wear of the mild steel, the mixing ratio of canola and syntactic oil had no influence, as pure canola oil revealed competitive wear performance, as did the various blends. Yet, the intermediate mixing ratio $(40 \%$ to $60 \%$ synthetic oil blended with $60 \%$ to $40 \%$ canola oil) generated slightly low SWR compared with the others

\section{Data Availability}

The tribology data used to support the findings of this study are included within the article.

\section{Conflicts of Interest}

The authors declare that they have no conflicts of interest.

\section{References}

[1] X. Cui, P. Cao, J. Guo, and P. Ming, "Use and performance of soybean oil based bio-lubricant in reducing specific cutting energy during biomimetic machining," Journal of Manufacturing Processes, vol. 62, pp. 577-590, 2021.

[2] G. Öncü and E. Durak, "Utilization of waste vegetable oil methyl esters as lubricant oil," Proceedings of the Institution of Mechanical Engineers - Part J: Journal of Engineering Tribology, vol. 235, no. 10, pp. 2144-2154, 2021.

[3] A. Dhanola and H. C. Garg, "Experimental analysis of the efficacy of vegetable oil-based nanolubricants for improving journal-bearing performance," Proceedings of the Institution of Mechanical Engineers - Part J: Journal of Engineering Tribology, vol. 235, no. 9, pp. 1974-1991, 2021.

[4] A. Shalwan, B. F. Yousif, F. H. Alajmi, K. R. Alrashdan, and M. Alajmi, "Tribological investigation of frictional behaviour of mild steel under canola bio-lubricant conditions," Tribology in Industry, vol. 42, no. 3, pp. 481-493, 2020.

[5] P. K. Sahoo and L. M. Das, "Combustion analysis of Jatropha, Karanja and Polanga based biodiesel as fuel in a diesel engine," Fuel, vol. 88, no. 6, pp. 994-999, 2009.

[6] D. Berthe, D. Dowson, M. Godet, and C. M. Taylor, Tribological Design of Machine Elements, Vol. 14, Elsevier, Amsterdam, Netherlands, 1989.

[7] G. Stachowiak and A. W. Batchelor, Experimental Methods in Tribology, Elsevier, 2004.

[8] L. Aguado-Deblas, R. Estevez, J. Hidalgo-Carrillo et al., "Outlook for direct use of sunflower and Castor oils as biofuels in compression ignition diesel engines, being part of diesel/ethyl acetate/straight vegetable oil triple blends," Energies, vol. 13, no. 18, p. 4836, 2020.

[9] S. Che Mat, M. Y. Idroas, M. F. Hamid, and Z. A. Zainal, "Performance and emissions of straight vegetable oils and its blends as a fuel in diesel engine: a review," Renewable and Sustainable Energy Reviews, vol. 82, pp. 808-823, 2018.

[10] S. Wen and P. Huang, Principles of Tribology, Wiley Online Library, Hoboken, NJ, USA, 2012.

[11] G. Stachowiak and A. W. Batchelor, Engineering Tribology, Butterworth-Heinemann, Oxford, UK, 2013.

[12] J. Williams, Engineering Tribology, Cambridge University Press, Cambridge, UK, 1994.

[13] H. Hirani, Fundamentals of Engineering Tribology with Applications, Cambridge University Press, Cambridge, UK, 2016.

[14] A. S. Ramadhas, S. Jayaraj, and C. Muraleedharan, "Use of vegetable oils as I. C. engine fuels-A review," Renewable Energy, vol. 29, no. 5, pp. 727-742, 2004.

[15] P. Nagendramma and S. Kaul, "Development of ecofriendly/ biodegradable lubricants: an overview," Renewable and Sustainable Energy Reviews, vol. 16, no. 1, pp. 764-774, 2012.

[16] J. O. Agunsoye, S. I. Talabi, O. Awe, and H. Kelechi, "Mechanical properties and tribological behaviour of recycled polyethylene/cow bone particulate composite," Journal of Materials Science Research, vol. 2, no. 2, p. p41, 2013.

[17] C.-Y. Lin, "Strategies for promoting biodiesel use in marine vessels," Marine Policy, vol. 40, pp. 84-90, 2013.

[18] A. M. Danilov, "Progress in research on fuel additives (review)," Petroleum Chemistry, vol. 55, no. 3, pp. 169-179, 2015.

[19] R. C. Rowe, P. J. Shesjey, and S. C. Owen, Pharmaceutical Excipients 5: Single-User Version, McGraw-Hill Medical Publishing Division, 2005.

[20] V. J. Barthet, "Canola: overview," in Encyclopedia of Food Grains, C. Wrigley, Ed., pp. 237-241, Academic Press, Oxford, UK, Second edition, 2016.

[21] L. Day, "Proteins from land plants - potential resources for human nutrition and food security," Trends in Food Science \& Technology, vol. 32, no. 1, pp. 25-42, 2013.

[22] A. A. Aachary, U. Thiyam-Hollander, and M. N. Eskin, "Canola/rapeseed proteins and peptides," in Applied Food Protein Chemistry, pp. 193-218, Wiley, Hoboken, NJ, USA, 2014.

[23] N. E. Bassam, Energy Plant Species: Their Use and Impact on Environment and Development, Routledge, London, UK, 2013.

[24] R. Przybylski, T. Mag, N. A. M. Eskin, and B. E. McDonald, Canola Oil. Bailey's Industrial Oil and Fat Products, Wiley Online Library, Hoboken, NJ, USA, 2005.

[25] C. A. Moses and P. N. Roets, "Properties, characteristics, and combustion performance of Sasol fully synthetic jet fuel," 
Journal of Engineering for Gas Turbines \& Power, vol. 131, no. 4, Article ID 041502, 2009.

[26] B. F. Yousif, "Design of newly fabricated tribological machine for wear and frictional experiments under dry/wet condition," Materials \& Design, vol. 48, pp. 2-13, 2013.

[27] L. A. Quinchia, M. A. Delgado, T. Reddyhoff, C. Gallegos, and H. A. Spikes, "Tribological studies of potential vegetable oil-based lubricants containing environmentally friendly viscosity modifiers," Tribology International, vol. 69, pp. 110-117, 2014.

[28] G. S. Vasyliev, "The influence of flow rate on corrosion of mild steel in hot tap water," Corrosion Science, vol. 98, pp. 33-39, 2015.

[29] X. Zheng, S. Zhang, W. Li, M. Gong, and L. Yin, "Experimental and theoretical studies of two imidazolium-based ionic liquids as inhibitors for mild steel in sulfuric acid solution," Corrosion Science, vol. 95, pp. 168-179, 2015.

[30] B. F. Yousif and N. S. M. El-Tayeb, "Wear and friction characteristics of CGRP composite under wet contact condition using two different test techniques," Wear, vol. 265, no. 5-6, pp. 856-864, 2008.

[31] M. Lindroos, K. Valtonen, A. Kemppainen, A. Laukkanen, K. Holmberg, and V.-T. Kuokkala, "Wear behavior and work hardening of high strength steels in high stress abrasion," Wear, vol. 322-323, pp. 32-40, 2015.

[32] M. Ruiz-Andres, A. Conde, J. de Damborenea, and I. Garcia, "Friction and wear behaviour of dual phase steels in discontinuous sliding contact conditions as a function of sliding speed and contact frequency," Tribology International, vol. 90, pp. 32-42, 2015.

[33] S. A. Alidokht, A. Abdollah-zadeh, and H. Assadi, "Effect of applied load on the dry sliding wear behaviour and the subsurface deformation on hybrid metal matrix composite," Wear, vol. 305, no. 1-2, pp. 291-298, 2013.

[34] M. A. Wimmer, M. P. Laurent, M. T. Mathew et al., "The effect of contact load on CoCrMo wear and the formation and retention of tribofilms," Wear, vol. 332-333, pp. 643-649, 2015.

[35] C. W. Chin and B. F. Yousif, "Potential of kenaf fibres as reinforcement for tribological applications," Wear, vol. 267, no. 9-10, pp. 1550-1557, 2009.

[36] N. A. Mat Tahir, M. F. B. Abdollah, R. Hasan, and H. Amiruddin, "The effect of sliding distance at different temperatures on the tribological properties of a palm kernel activated carbon-epoxy composite," Tribology International, vol. 94, pp. 352-359, 2016.

[37] R. G. Bayer, Engineering Design for Wear, CRC Press, Boca Raton, FL, USA, Second edition, 2004.

[38] M. Scherge, D. Linsler, and T. Schlarb, "The running-in corridor of lubricated metal-metal contacts," Wear, vol. 342-343, pp. 60-64, 2015.

[39] F. Bowden and E. Freitag, "The friction of solids at very high speeds. I. Metal on metal; II. Metal on diamond," in Proceedings of the Royal Society of London A: Mathematical, Physical and Engineering Sciences, The Royal Society, London, UK, March 1958.

[40] J. G. Alotaibi and B. F. Yousif, "Biolubricants and the potential of waste cooking oil," in Ecotribology, pp. 125-143, Springer, Berlin, Germany, 2016.

[41] J. T. Araruna Jr, V. L. Portes, A. P. Soares et al., "Oil spills debris clean up by thermal desorption," Journal of Hazardous Materials, vol. 110, no. 1-3, pp. 161-171, 2004.
[42] L. Tang, J. Xiong, W. Wan et al., "The effect of fluid viscosity on the erosion wear behavior of $\operatorname{Ti}(\mathrm{C}, \mathrm{N})$-based cermets," Ceramics International, vol. 41, no. 3, pp. 3420-3426, 2015. 